\title{
Prognostic Factors in Early-stage NSCLC: Analysis of the Placebo Group in the MAGRIT Study
}

\author{
BYOUNG CHUL CHO ${ }^{1}$, TOMMASO DE PAS ${ }^{2}$, HARALABOS KALOFONOS ${ }^{3}$, QUN WANG ${ }^{4}$, RODRYG RAMLAU $^{5}$, \\ YING CHENG $^{6}$, FABIANA VITIELLO ${ }^{7}$, TANEL LAISAAR ${ }^{8}$, ERIC VALLIÈRES $^{9}$, BARTOSZ KUBISA ${ }^{10}$, \\ SERGEY ORLOV ${ }^{11}$, KEUNCHIL PARK $^{12}$, CHANNA DEBRUYNE $^{13}$ and JOHAN VANSTEENKISTE ${ }^{14}$ \\ ${ }^{1}$ Yonsei Cancer Center, Yonsei University College of Medicine, Seoul, Republic of Korea; \\ ${ }^{2}$ European Institute of Oncology IRCCS, Milan, Italy; \\ ${ }^{3}$ University Hospital of Patras, Patras, Greece; \\ ${ }^{4}$ Zhongshan Hospital Fudan University, Shanghai, P.R. China; \\ ${ }^{5}$ Wielkopolskie Center for Disease Plague and Tuberculosis, Poznan, Poland; \\ ${ }^{6} J$ ilin Provincial Cancer Hospital, Changchun, P.R. China; \\ ${ }^{7}$ V. Monaldi Hospital, AORN dei Colli, Naples, Italy; \\ ${ }^{8}$ Lung Clinic, Tartu University Hospital, Tartu, Estonia; \\ ${ }^{9}$ Swedish Cancer Institute, Seattle, WA, U.S.A.; \\ ${ }^{10}$ Pomeranian Medical University of Szczecin, SPWSZ, Szczecin, Poland; \\ ${ }^{11}$ Pavlov State Medical University, St. Petersburg, Russian Federation; \\ ${ }^{12}$ Samsung Medical Center, Sungkyunkwan University School of Medicine, Seoul, Republic of Korea; \\ ${ }^{13}$ GSK, Rixensart, Belgium (Present address: University Hospitals KU Leuven, Leuven, Belgium; \\ ${ }^{14}$ University Hospitals KU Leuven, Leuven, Belgium
}

\begin{abstract}
Background/Aim: The analysis of prognostic factors is important to identify determinants of disease-free survival (DFS) and overall survival (OS) in resected nonsmall-cell lung cancer (NSCLC). Patients and Methods: We examined baseline characteristics associated with DFS and OS among 757 patients with resected, histologically proven, MAGE-A3-positive Stage IB-IIIA NSCLC assigned to placebo in the MAGRIT study (NCT00480025). We explored characteristics of NSCLC that could predict DFS and OS using Cox regression models. Results: The multivariate analysis showed that lower nodal stage, the presence of squamous cell carcinoma (SCC), a broader surgical resection in patients with SCC, and being female with non-SCC were significantly associated with longer DFS. Lower nodal stage and smaller tumor size were significantly associated with an
\end{abstract}

This article is freely accessible online.

Correspondence to: Byoung Chul Cho, Yonsei Cancer Center, Yonsei University College of Medicine, 50 Yonsei-ro, SeodaemunGu, Seoul 120-752, Republic of Korea. Tel: +82 1052128867, e-mail: cbc1971@yuhs.ac

Key Words: Non-small cell lung cancer, MAGE-A3 cancer immunotherapeutic, prognostic factors, placebo, overall survival. improved OS. Compared to Other International, enrollment in East Asia was associated with an improved OS in patients with non-SCC. Conclusion: This is the first prognostic factor analysis in NSCLC performed on data from a large prospective study. These results confirm retrospective studies and add that histopathology subtype is a strong determinant of DFS in resected MAGE-A3-positive NSCLC.

Lung cancer is the most frequent cause of death due to cancer, and non-small-cell lung cancer (NSCLC) accounts for $85 \%$ of all lung cancer cases (1). We have previously reported the results of the MAGRIT study, the largest therapeutic trial ever conducted in patient with lung cancer (2). MAGRIT was a global, multi-centre, phase-3 doubleblind, placebo-controlled, randomized trial to evaluate the efficacy of the MAGE-A3 cancer immunotherapeutic investigational product in patients with resected NSCLC (www.clinicaltrials.gov NCT00480025). From 18 Oct 2007 we enrolled and treated (2:1 randomization) 2,272 patients in 34 countries with up to 13 intramuscular injections of the MAGE-A3 immunotherapeutic drug or placebo over a period of 27 months. Patients were followed-up for chemotherapy use, clinical and disease outcomes for up to 5 years.

Treatment with the MAGE-A3 immunotherapeutic showed no effect in terms of disease-free survival (DFS), overall survival (OS) or any other clinical outcome 
measures. Overall median DFS was 60.5 months [95\% confidence interval $(\mathrm{CI})=57.2-$ not reached] in the treatment group and 57.9 months (55.7-not reached) in the placebo group [hazard ratio $(\mathrm{HR})=1.02,95 \% \mathrm{CI}=0.89-1.18, p=0.74]$. Median OS was not reached in either group $(\mathrm{HR}=1.04$, $95 \% \mathrm{CI}=0.86-1.24 ; p=0.70)(2)$. A gene signature predictive of clinical benefit to the MAGE-A3 immunotherapeutic (coprimary objective) could not be identified (2).

There were 757 patients assigned to the placebo group in the MAGRIT study, for whom detailed information on demographic characteristics, disease stage, surgical treatment and clinical outcomes over an extended follow-up period were collected. This is one of the largest prospective datasets that can be used to provide important insights into factors influencing disease prognosis. We conducted an exploratory search for potential clinical prognostic factors for DFS and OS in resected NSCLC in the MAGRIT placebo population and confirmed these results by analysing the total (treatment group plus placebo group) study population.

\section{Patients and Methods}

Patients. Study participants were aged $\geq 18$ years with histologically -proven, MAGE-A3-positive stage IB, II or IIIA NSCLC (American Joint Committee on Cancer, AJCC 6.0). Participants had undergone anatomical lung resection (lobectomy or pneumonectomy) with mediastinal lymph node (LN) dissection or sampling, according to standard of care. Up to four platinum-based adjuvant chemotherapy cycles were allowed.

Patients gave written informed consent for MAGE-A3 expression screening, gene expression profiling, and for study participation. The study was conducted according to Good Clinical Practice, the Declaration of Helsinki, US FDA Code of Federal Regulations (title 21 part 50 and 56), and local rules and regulations of the participating countries. The protocol was approved by national, regional, or investigational centre institutional review boards or ethics committees.

Analysis methodology. The binary variables for analysis were: i) administration of adjuvant chemotherapy (yes/no), ii) ECOG (Eastern Cooperative Oncology Group) performance status (0-1/2), iii) gender (male/female), iv) histopathological type (squamous cell carcinoma [SCC]/non-SCC), v) operative technique (pneumonectomy/other), and vi) type of $\mathrm{LN}$ sampling (limited or minimal/systematic). The categorical variables were: i) disease stage (IB/II/IIIA), ii) region (East Asia/Europe/North America/Other International), iii) race, iv) smoking status at randomization (never/past/current), and v) type of chemotherapy received (none/vinorelbine+cisplatin/other). The ordered categorical variables were: i) nodal stage (N0/N1/N2-3-x), ii) number of chemotherapy cycles (none/1-2/3-4), and iii) tumour stage $(0-1 / 2 / 3-4)$. Age, MAGE-A3 quantitative expression and tumour size were treated as continuous variables.

Univariate and multivariate analyses were conducted to determine which factors are associated with DFS and OS. The Cox model was used to model the Hazard $(\mathrm{H}(\mathrm{t}))$ as follows:

$\mathrm{H}(\mathrm{t})=\mathrm{H}_{0}(\mathrm{t}) \exp \left(\beta_{1} \mathrm{Z}_{1}+\beta_{2} \mathrm{Z}_{2}+\beta_{3} \mathrm{Z}_{3}+\ldots+\beta_{\mathrm{k}} \mathrm{Z}_{\mathrm{k}}\right)$

where $Z_{1} \ldots Z_{k}$ are a collection of predictor variables and $\mathrm{HO}(\mathrm{t})$ is the baseline hazard at time $t$, representing the hazard for a person with value 0 for all predictor variables.
Univariate analyses were conducted for DFS and OS (and in subgroups according to histological cancer type). Using the variables significant at $p \leq 0.05$ in the univariate analysis, a multivariate model was built using a stepwise approach. The most significant variables were added sequentially to the model, while checking whether the variables added at the previous step were still significant once other variables had been entered. Simple Forward and Backward selection procedures were used to check for consistency between models.

The analysis did not account specifically for missing data as very few baseline data were missing.

Prognostic models for DFS and OS were constructed based on the patients in the placebo population. Models using all patients (treatment group and placebo), stratified by treatment group, were also tested. Models on the total population were not used to draw conclusions, because even in the absence of a global treatment effect, the existence of small treatment effect in specific subgroups could not be excluded.

\section{Results}

Characteristics of the placebo population in the MAGRIT study. All patients enrolled in the MAGRIT study were MAGE-A3-positive. Among placebo recipients, 401 (53\%) had SCC and 356 (47\%) had non-SCC (Table I). Most patients $(644 / 757,85 \%)$ underwent lobectomy (including bilobectomy and sleeve lobectomy) and 113 patients (15\%) had a pneumonectomy. Mediastinal LN dissection was performed in 355/757 (47\%) and LN sampling in 402 (53\%). There were $392 / 757(52 \%)$ patients who received adjuvant platinum-based chemotherapy.

The median follow-up of the placebo population was 39.5 months (interquartile range=27.9-50.4). At the time of the final analysis, there were 271 disease recurrences amongst placebo recipients and a further 27 deaths in the absence of recurrence.

Demographic characteristics of the placebo population were similar to those of the overall population (2).

Analysis of the placebo population. In the univariate analysis of the placebo population, lower nodal stage and earlier disease stage were identified as associated with improved DFS ( $p=0.0001$ for nodal stage $\mathrm{N} \geq 2$ versus $\mathrm{N} 1$, and N1 versus N0 and $p=0.0033$ for pathological stage $\geq$ IIIA versus $\leq \mathrm{IB}$ ). Lower nodal stage, earlier disease stage and smaller tumour size were identified as associated with improved OS ( $p=0.0002$ for nodal stage, $p=0.0022$ for pathological stage and $p=0.0247$ for tumour size). There was a prognostic impact of histopathology on DFS (but not on OS), with longer DFS in patients with SCC than with non-SCC (Figure 1). In view of the different nature of the diseases, we focused the multivariate analyses on SCC and non-SCC groups separately.

In the multivariate analysis for DFS, lower nodal stage (HR for $\mathrm{N} \geq 2$ versus $\mathrm{N} 1$, and $\mathrm{N} 1$ versus $\mathrm{N} 0=1.34,95 \% \mathrm{CI}=1.16$ - 
Table I. Demographic and disease characteristics of the placebo group (Total cohort - as treated).

\begin{tabular}{lc}
\hline Characteristics & Placebo N=757 \\
\hline Age at screening (years) & \\
Mean (IQR) & $63(57-70)$ \\
Gender n (\%) & $179(24 \%)$ \\
Female & $578(76 \%)$ \\
Male & \\
Histopathology & $401(53 \%)$ \\
Squamous & $356(47 \%)$ \\
Non-squamous & \\
Performance status n (\%) & $440(58 \%)$ \\
0 & $300(40 \%)$ \\
1 & $17(2 \%)$ \\
2 & \\
Tumour stage n (\%) & $346(46 \%)$ \\
IB & $275(36 \%)$ \\
II & $134(18 \%)$ \\
IIIA & $2(<1 \%)$ \\
Other - Ineligible & $392(52 \%)$ \\
Adjuvant chemotherapy & $365(48 \%)$ \\
Yes & \\
No & $162(41 \%)$ \\
Type of chemotherapy & $230(59 \%)$ \\
Cisplatin-Vinorelbine & \\
Other & $113(15 \%)$ \\
Type of surgery & $644(85 \%)$ \\
Pneumonectomy & $355(47 \%)$ \\
Lobectomy/Bi- or Sleeve lobectomy & $402(53 \%)$ \\
Lymph node surgery & \\
Mediastinal lymph node dissection & $39(7 \%)$ \\
Lymph node sampling & $400(40 \%)$ \\
Lifetime smoking status* & \\
Never smoked & \\
Past smoker & \\
Current smoker & \\
Region & $(24 \%)$ \\
East Asia & \\
Europe & \\
North America & \\
Other International & \\
\hline
\end{tabular}

$\mathrm{N}$ : Total number of patients; $\mathrm{n}(\%)$ : number (percentage) of patients with the defined characteristic; IQR: interquartile range; *Never smoker: has smoked $\leq 100$ cigarettes in entire lifetime and stopped or never smoked cigarettes; Current smoker: has smoked $>100$ cigarettes in entire lifetime and is either currently smoking or quit smoking $<1$ year ago; Past smoker: has smoked $>100$ cigarettes in entire lifetime and quit smoking $\geq 1$ year ago.

1.55) and SCC (HR for SCC versus non-SCC $=0.64$, $95 \% \mathrm{CI}=0.51-0.81)$ remained significant $(p=0.0001)$ (Table II). In the analysis for OS, lower nodal stage and smaller tumour size were significantly associated with improved OS [HR for $\mathrm{N} \geq 2$ versus $\mathrm{N} 1$, and $\mathrm{N} 1$ versus $\mathrm{N} 0=1.47,95 \% \mathrm{CI}=1.21-1.79$ $(p=0.0001)$, and HR by unit increase $=1.08,95 \% \mathrm{CI}=1.01-1.15$ $(p=0.0188)]$, respectively] (Table II).
Placebo population with SCC. Among patients with MAGEA3-positive SCC, the univariate analysis identified that an increased number of chemotherapy cycles and the operative technique (pneumonectomy) were associated with an improved DFS ( $p=0.0356$ for 3-4 cycles versus 1-2 cycles, and 1-2 cycles versus none, and $p=0.0275$ for pneumonectomy versus other). Lower nodal stage and smaller tumour size were significantly associated with improved OS ( $p=0.0088$ for nodal stage $\mathrm{N} \geq 2$ versus $\mathrm{N} 1$, and $\mathrm{N} 1$ versus $\mathrm{N0}$, and $p=0.0344$ for tumour size).

In the multivariate model, only the extent of surgical resection remained associated with improved DFS (HR for pneumonectomy versus other $=0.56,95 \% \mathrm{CI}=0.33-0.94)$, while lower nodal stage and smaller tumour size were associated with longer $\mathrm{OS}$ ( $\mathrm{HR}$ for $\mathrm{N} \geq 2$ versus $\mathrm{N} 1$, and $\mathrm{N} 1$ versus $\mathrm{N} 0=1.50$, $95 \% \mathrm{CI}=1.11-2.02$, HR by unit increase in tumour size $=1.10$, 95\% CI $=1.00-1.20$ ) (Table II). When allowing parameters that were borderline in the univariate analysis into the model of patients with SCC (i.e. nodal stage $p=0.0918$ and administration of chemotherapy $p=0.0628$ in the univariate analysis), three variables were significant at $p \leq 0.05$ for DFS. These were: i) nodal stage ( $\mathrm{HR}$ for $\mathrm{N} \geq 2$ versus $\mathrm{N} 1$, and $\mathrm{N} 1$ versus $\mathrm{N} 0=1.61$, $95 \% \mathrm{CI}=1.22-2.11)$, ii) an increased number of chemotherapy cycles (HR for 3-4 cycles versus 1-2 cycles, and 1-2 cycles versus none $=0.72,95 \% \mathrm{CI}=0.59-0.89)$ and iii) the extent of surgical resection (HR for pneumonectomy versus other $=0.51$, $95 \% \mathrm{CI}=0.30-0.87$ ). Forward and backward selection processes selected the same variables in each analysis.

Placebo population with non-SCC. Among patients with MAGE-A3-positive non-SCC, univariate analysis identified improved DFS in the following groups: i) younger age, ii) female gender, iii) lower nodal stage and iv) earlier disease stage ( $p=0.0321$ for age, $p=0.0345$ for male versus female gender, $p=0.0003$ for nodal stage $\mathrm{N} \geq 2$ versus $\mathrm{N} 1$, and $\mathrm{N} 1$ versus $\mathrm{N} 0$, and $p=0.0049$ for pathological stage $\geq$ IIIA versus $\leq \mathrm{IB}$ ). Lower nodal stage, earlier disease stage and region (East Asia) were associated with improved OS in the univariate analysis ( $p=0.0088$ for nodal stage, $p=0.0223$ for pathological stage, and $p=0.0427$ for Other International versus East Asia).

Lower nodal stage and female gender remained significant in the multivariate analysis for DFS [HR for $\mathrm{N} \geq 2$ versus $\mathrm{N} 1$, and $\mathrm{N} 1$ versus $\mathrm{N} 0=1.42,95 \% \mathrm{CI}=1.17-1.71(p=0.0003), \mathrm{HR}$ for male versus female $=1.44,95 \% \mathrm{CI}=1.03-2.02(p=0.0354)]$ (Table II). Nodal stage $[(\mathrm{HR}=1.48,95 \% \mathrm{CI}=1.14-1.92$ $(p=0.0032)]$ and region remained significant in the multivariate analysis for OS (HR for Europe versus East Asia $=1.53,95 \% \mathrm{CI}=0.88-2.68$, North America versus East Asia $=1.17,95 \% \mathrm{CI}=0.58-2.36$, Other International versus East Asia=3.48, 95\% CI=1.54-7.86 $(p=0.0194)]$. In the forward and backward selection processes, backward analysis selected the disease stage instead of the nodal stage, but these variables are known to be correlated. 


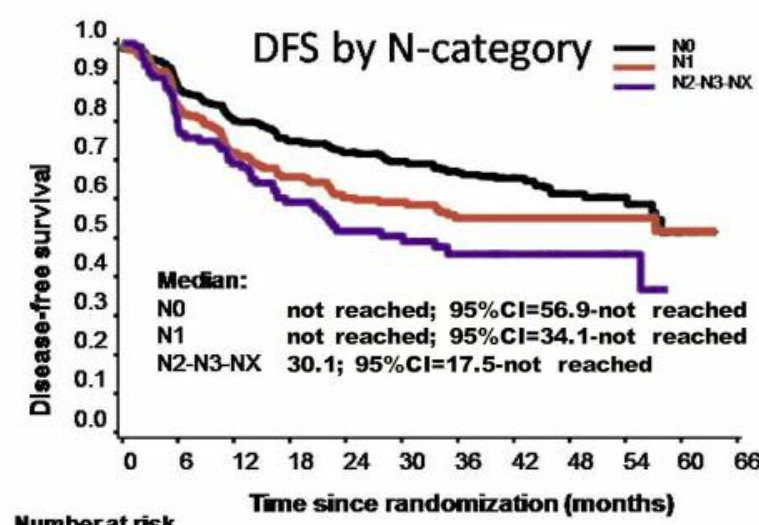

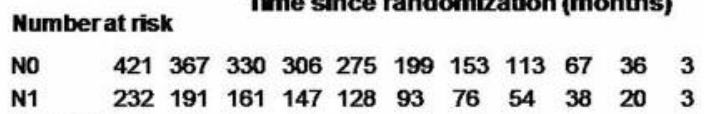

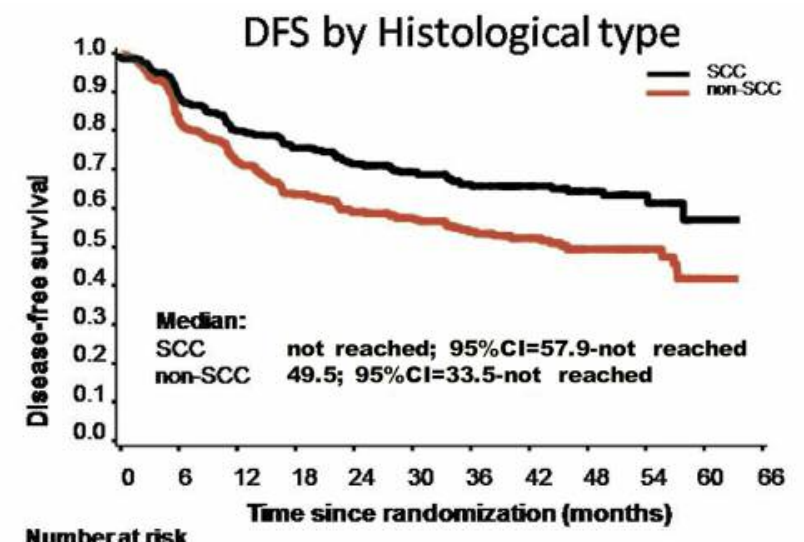

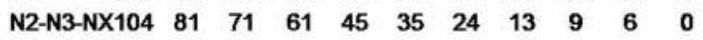

$\begin{array}{llllllllllll}\text { SCC } & 401 & 350 & 312 & 293 & 263 & 189 & 147 & 100 & 71 & 34 & 2\end{array}$

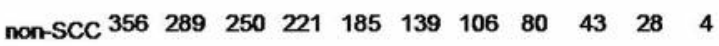
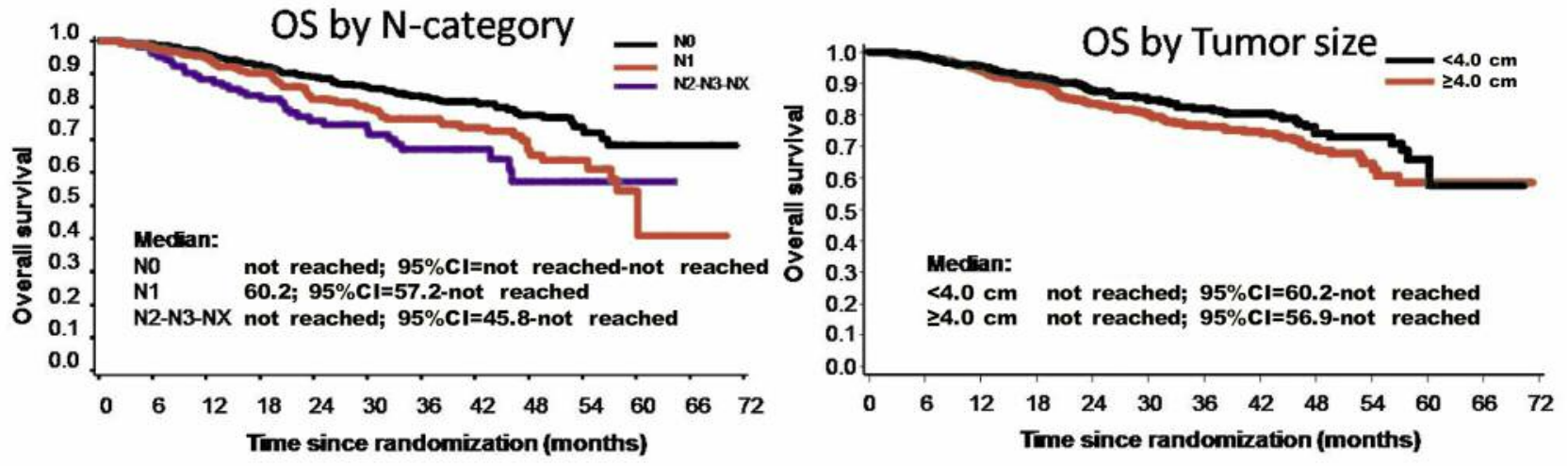

Numberat risk
$\begin{array}{lllllllllllll}\text { No } & 421 & 408 & 392 & 373 & 336 & 248 & 192 & 143 & 88 & 45 & 9 & 4 \\ \text { N1 } & 232 & 224 & 211 & 198 & 170 & 128 & 103 & 68 & 44 & 25 & 4 & 1 \\ \text { N2-N3-NX104 } & 99 & 90 & 83 & 64 & 51 & 35 & 24 & 13 & 8 & 1 & 0\end{array}$

Numberat risk

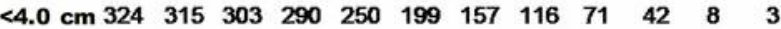

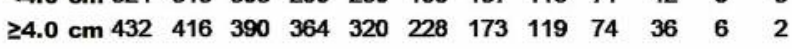

Figure 1. Disease-free survival (DFS) by nodal stage and by histological type, and overall survival (OS) by nodal stage and by tumour size in the placebo population. SCC: Squamous-cell carcinoma; Non-SCC: non squamous cell carcinoma; $95 \%$ CI: 95\% confidence interval.

Prognostic analysis for the total study population. In the univariate analysis of the total population, the lower nodal stage and the earlier pathological stage were identified as associated with improved DFS, whereas quantitative MAGEA3 expression and past or current smoking were associated with reduced DFS $(p \leq 0.0371$ for all). Age, ECOG performance status $>1$ versus $\leq 1$, female versus male gender, nodal stage, pathological stage and tumour size were identified as associated with improved OS ( $p \leq 0.0341$ for all). As observed in the placebo population, there was a prognostic impact of histopathology on DFS and on OS, with longer DFS in patients with SCC than with non-SCC $(p<0.0001$ for DFS and $p=0.0015$ for OS $)$.

In the multivariate analysis for DFS, lower nodal stage $(p<0.0001)$ and SCC $(p<0.0001)$ remained significant (Table II). In the analysis for OS, age $(p<0.0001)$, ECOG performance status $>1$ versus $\leq 1 \quad(p=0.0192)$, female versus male gender $(p=0.0216)$, disease stage $(p<0.0001)$ and tumour size $(p<0.0001)$ were significantly associated with an improved OS (Table II).

In patients with MAGE-A3-positive SCC, the univariate analysis identified: i) lower ECOG score, ii) lower nodal state, iii) lower disease stage, iv) administration of chemotherapy, v) increased chemotherapy cycles, vi) the type of chemotherapy received, and vii) having never smoked, as significantly associated with improved DFS ( $p \leq 0.0420$ for all). In patients with MAGE-A3-positive non-SCC, younger age, lower nodal stage, lower disease stage, smaller tumour size and enrolment in East Asia, were associated with improved DFS in the univariate analysis $(p \leq 0.0342$ for all).

In patients with MAGE-A3-positive SCC, younger age, ECOG performance status of $\leq 1$, lower nodal stage, lower 
Table II. Cox models for disease-free survival (DFS) and overall survival (OS) in the placebo and total populations (stepwise approach), overall and according to histological type, based on baseline variables that were significant (level 0.05) at the univariate level.

\begin{tabular}{|c|c|c|c|c|c|c|c|}
\hline \multirow{2}{*}{$\begin{array}{l}\text { Placebo population } \\
\text { Parameter }\end{array}$} & \multicolumn{7}{|c|}{ Total population (placebo + treatment groups) } \\
\hline & $\begin{array}{l}\text { Parameter } \\
\text { estimate }\end{array}$ & $p$-Value & HR $(95 \% \mathrm{CI})$ & Parameter & $\begin{array}{l}\text { Parameter } \\
\text { estimate }\end{array}$ & $p$-Value & HR $(95 \% \mathrm{CI})$ \\
\hline DFS & & & & DFS & & & \\
\hline $\begin{array}{l}\text { Histopathological type: } \\
\text { SCC (versus } \text { Non-SCC) }\end{array}$ & -0.44333 & 0.0001 & $0.642(0.511-0.807)$ & $\begin{array}{l}\text { Histopathological type: } \\
\text { SCC (versus Non-SCC) }\end{array}$ & -0.48668 & $<0.0001$ & $0.615(0.538-0.702)$ \\
\hline $\begin{array}{l}\text { Nodal stage } \\
\text { SCC }\end{array}$ & 0.29285 & 0.0001 & $1.340(1.156-1.554)$ & $\begin{array}{l}\text { Nodal stage } \\
\text { SCC }\end{array}$ & 0.36154 & $<0.0001$ & $1.436(1.316-1.566)$ \\
\hline Operative technique: & -0.58870 & 0.0275 & $0.555(0.329-0.937)$ & Nodal stage & 0.48203 & $<0.0001$ & $1.619(1.387-1.891)$ \\
\hline Pneumonectomy (versus Other) & & & & $\begin{array}{l}\text { Number of cycles of } \\
\text { adjuvant chemotherapy } \\
\text { Non-SCC }\end{array}$ & -0.27622 & $<0.0001$ & $0.759(0.677-0.851)$ \\
\hline Nodal stage & 0.34759 & 0.0003 & $1.416(1.173-1.708)$ & Age & 0.01348 & 0.0066 & $1.014(1.004-1.023)$ \\
\hline \multirow{5}{*}{ Gender: Male (versus Female) } & 0.36504 & 0.0354 & $1.441(1.025-2.024)$ & Nodal stage & 0.37501 & $<0.0001$ & $1.455(1.302-1.626)$ \\
\hline & & & & $\begin{array}{l}\text { Region: Europe } \\
\text { (versus } \text { East Asia) }\end{array}$ & -0.05096 & 0.0378 & $0.950(0.764-1.182)$ \\
\hline & & & & $\begin{array}{l}\text { Region: North America } \\
\text { (versus East Asia) }\end{array}$ & -0.11685 & & $0.890(0.669-1.183)$ \\
\hline & & & & $\begin{array}{l}\text { Region: Other International } \\
\text { (versus East Asia) }\end{array}$ & 0.46945 & & $1.599(1.076-2.378)$ \\
\hline & & & & Tumour size & 0.05060 & 0.0090 & $1.052(1.013-1.093)$ \\
\hline OS & & & & OS & & & \\
\hline Nodal stage & 0.38598 & 0.0001 & $1.471(1.210-1.789)$ & $\begin{array}{l}\text { Pathological stage: II } \\
\text { (versus IB or less) }\end{array}$ & 0.50680 & $<0.0001$ & $1.660(1.356-2.033)$ \\
\hline \multirow[t]{6}{*}{ Tumour size } & 0.07529 & 0.0188 & $1.078(1.013-1.148)$ & $\begin{array}{l}\text { Pathological stage: IIIA } \\
\text { or more (versus IB or less) }\end{array}$ & 0.87171 & & $2.391(1.906-2.999)$ \\
\hline & & & & Tumour size & 0.04250 & 0.0244 & $1.043(1.006-1.083)$ \\
\hline & & & & $\begin{array}{l}\text { Histopathological type: } \\
\text { SCC (versus } \text { Non-SCC) }\end{array}$ & -0.41596 & $<0.0001$ & $0.660(0.552-0.788)$ \\
\hline & & & & $\begin{array}{l}\text { Gender - Male } \\
\text { (versus Female) }\end{array}$ & 0.25612 & 0.0216 & $1.292(1.038-1.607)$ \\
\hline & & & & $\begin{array}{l}\text { ECOG performance status: } \\
>1(\text { versus } 0 \text { or } 1)\end{array}$ & 0.56617 & 0.0192 & $1.762(1.097-2.830)$ \\
\hline & & & & Age & 0.02449 & $<0.0001$ & $1.025(1.015-1.035)$ \\
\hline SCC & & & & SCC & & & \\
\hline Nodal stage & 0.40405 & 0.0084 & $1.498(1.109-2.023)$ & Nodal stage & 0.50905 & $<0.0001$ & $1.664(1.395-1.985)$ \\
\hline \multirow[t]{3}{*}{ Tumour size } & 0.09325 & 0.0463 & $1.098(1.002-1.203)$ & Age & 0.02285 & 0.0040 & $1.023(1.007-1.039)$ \\
\hline & & & & $\begin{array}{l}\text { ECOG performance status: } \\
>1(\text { versus } 0 \text { or } 1)\end{array}$ & 0.59856 & 0.0456 & $1.819(1.012-3.272)$ \\
\hline & & & & Tumour stage & 0.53251 & $<0.0001$ & $1.703(1.322-2.194)$ \\
\hline Non-SCC & & & & Non-SCC & & & \\
\hline \multirow[t]{2}{*}{ Nodal stage } & 0.39125 & 0.0032 & $1.479(1.140-1.918)$ & $\begin{array}{l}\text { Pathological stage: } \\
\text { II (versus IB or less) }\end{array}$ & 0.57585 & $<0.0001$ & $1.779(1.352-2.340)$ \\
\hline & & & & $\begin{array}{l}\text { Pathological stage: IIIA } \\
\text { or more (versus IB or less) }\end{array}$ & 0.88826 & & $2.431(1.787-3.307)$ \\
\hline $\begin{array}{l}\text { Region: Europe } \\
\text { (versus } \text { East Asia) }\end{array}$ & 0.42593 & 0.0194 & $1.531(0.874-2.682)$ & $\begin{array}{l}\text { Region - Europe } \\
\text { (versus } \text { East Asia) }\end{array}$ & 0.35535 & 0.0003 & $1.427(1.042-1.953)$ \\
\hline $\begin{array}{l}\text { Region: North America } \\
\text { (versus East Asia) }\end{array}$ & 0.15640 & & $1.169(0.580-2.356)$ & $\begin{array}{l}\text { Region - North America } \\
\text { (versus East Asia) }\end{array}$ & 0.06314 & & $1.065(0.700-1.621)$ \\
\hline \multirow[t]{3}{*}{$\begin{array}{l}\text { Region: Other International } \\
\text { (versus East Asia) }\end{array}$} & 1.24743 & & $3.481(1.542-7.860)$ & $\begin{array}{l}\text { Region: Other International } \\
\text { (versus East Asia) }\end{array}$ & 1.06054 & & $2.888(1.733-4.812)$ \\
\hline & & & & Age & 0.02841 & $<0.0001$ & $1.029(1.015-1.043)$ \\
\hline & & & & $\begin{array}{l}\text { Gender: Male } \\
\text { (versus } \text { Female) }\end{array}$ & 0.39687 & 0.0056 & $1.487(1.123-1.969)$ \\
\hline
\end{tabular}

SCC: Squamous cell carcinoma; non-SCC: non-squamous cell carcinoma; ECOG: Eastern Cooperative Oncology Group; HR: hazard ratio coming from a Cox regression model, with the Efron method to handle ties; 95\%CI: 95\% confidence interval; $p$-Value: Two-sided $p$-value from a Wald test. 
disease stage, lower tumour stage and smaller tumour size were significantly associated with an improved OS $(p \leq 0.0341$ for all). In patients with non-SCC, age, gender, nodal stage, earlier disease stage, reduced tumour size and region (East Asia) were associated with improved OS, whereas pneumonectomy was associated with a reduced OS ( $p \leq 0.0439$ for all).

Nodal stage and the number of chemotherapy cycles remained associated in the multivariate model of DFS for the total population of patients with MAGE-A3-positive SCC (Table II) $(p<0.0001)$. Age, nodal stage, tumour stage and ECOG performance status remained associated in the multivariate model of OS for patients with MAGE-A3positive SCC (Table II) ( $p \leq 0.0456$ for all).

Nodal stage was the only common variable selected in the placebo and total population analyses of DFS for patients with MAGE-A3-positive non-SCC. Only nodal stage in the SCC population, and region in the non-SCC populations were common variables selected in the analyses of OS in the placebo and total populations (Table II). There was no consistency in the selection of other variables when we compared the models obtained using placebo versus the total population.

\section{Discussion}

This is the first prognostic factor analysis in resected NSCLC performed on data from a large prospective study. Using a unique repository of prospectively collected data from patients with completely resected NSCLC, we were able to identify tumour characteristics and treatment factors linked to improved prognosis in terms of DFS and OS. Tumour and disease characteristics associated with an improved prognosis were: i) histological subtype, ii) nodal stage and iii) tumour size. The results suggest that patients with MAGE-A3-positive SCC had a better prognosis than those with MAGE-A3-positive non-SCC in terms of DFS, but not of OS. Nodal stage played a major role in defining prognosis (DFS and OS) for patients with both histological types. Treatment parameters (the number of chemotherapy cycles and the extent of surgical resection) were only associated with an improved DFS prognosis in patients with MAGE-A3-positive SCC. Enrolment in East Asia was associated with an improved OS whereas enrolment in Europe or North America was associated with an improved DFS (univariate analysis only), although we observed no significant associations with ethnicity in this study. These last results are inconclusive, but differences between countries could potentially arise from differences in access to treatment and in treatment practices.

Smaller, retrospective studies have not identified consistent associations between DFS and disease or treatment characteristics. For example, improved DFS has been associated with tumour size and total metastatic LN ratio (not captured in our study), but not with histologic type (3). In another study, DFS was associated with lymphovascular invasion (not captured in our study), the extent of surgical resection and age (4). We identified one study that showed a poorer prognosis in patients with SCC compared with nonSCC NSCLC (5).

In our study, nodal stage played a major role in defining prognosis in the placebo population and in the total MAGRIT study population, regardless of the histopathology. This is consistent with a large retrospective study of patients with NSCLC using the Surveillance, Epidemiology, and End Results database in the United States, which found that the number of positive LNs or their ratio versus negative LNs were independent indicators of survival (6). In Japanese patients with N2 NSCLC, the LN ratio was identified as an important indicator of poor prognosis (7). However, in patients with T1 tumours, positive LNs were inversely associated with OS only in patients with adenocarcinoma, but not with SCC (8).

Although we observed an improved DFS in patients with SCC who underwent pneumonectomy over lobectomy, this was only observed in the placebo group and it was not confirmed in the analysis of the total population. Conversely, although not significant in the multivariate analysis, pneumonectomy was associated with a reduced OS in the total population with nonSCC. A study in patients with stage II NSCLC showed no difference in survival between the two techniques (9), and a meta-analysis concluded that sleeve lobectomy gave better long term survival compared to pneumonectomy (10). However, these studies did not discriminate by histological type and it is difficult to compare our results with theirs. Based on our results, it is not clear whether pneumonectomy may confer some advantage according to histological type, nor the biological basis for such an effect.

A potential limitation of our study is that we focused on clinical and treatment factors and a limited number of demographic features but we did not consider other potential exposures (such as environmental or genetic). Furthermore, all patients were MAGE-A3 positive, which skewed the distribution of the histological type because MAGE-A3 expression is higher in SCC than in non-SCC. Validation of our results on an external database not limited to MAGE-A3 positive patients would be of interest, even though no prognostic value of MAGE-A3-expression has been observed in patients with NSCLC (11). A study evaluating a prognostic gene signature of molecular biomarkers and gene expression in the MAGRIT study has been performed (paper in preparation).

Strengths of the study are the large number of patients studied from heterogeneous settings that encompassed 443 clinics in 34 different countries. In contrast to existing reports, demographic, clinical, pathological and treatment characteristics were prospectively gathered during the MAGRIT study using standardized data collection forms. Finally, stratification of results by histopathology subtype adds new information compared to what is currently known.

In conclusion, our results confirm those of the retrospective studies and add that the histopathology subtype 
is a strong determinant for DFS in resected MAGE-A3positive NSCLC. Patients with MAGE-A3-positive SCC had a better DFS (but not OS) compared to those with non-SCC. Identification of prognostic factors will help identify risk in these patients and guide appropriate treatment.

\section{Funding}

This work was supported by GlaxoSmithKline Biologicals SA that funded all costs associated to the study and the development and publishing of the present manuscript.

\section{Conflicts of Interest}

JV reports having been on GSK advisory Board. BK and EV report receiving fees from GSK during the conduct of the study. CD was an employee of the GSK group of companies at the time of the study and holds shares in the GSK group of companies. BCC reports receiving grants and/or fees from AstraZeneca, Novartis, BMS/ONO, YUHAN, MSD and Behringer Ingelheim outside the submitted work. KP reports receiving grants and/or fees from Astellas, AZ, Clovis, Eli Lilly, Hanmi, Novartis, ONO and BI Roche outside of the submitted work. RR reports fees from Eli Lilly, Boehringer, Roche and MSD outside the submitted work. YC, HK, TL, SO, TDP, FV, QW have nothing to disclose.

\section{Authors' Contributions}

$\mathrm{BCC}, \mathrm{TDP}, \mathrm{SO}, \mathrm{KP}, \mathrm{EV}, \mathrm{CD}, \mathrm{JV}$ were involved in the conception/design of the study. BCC, TDP, QW, RR, YC, FV, TL, EV, $\mathrm{BK}, \mathrm{SO}, \mathrm{KP}, \mathrm{CD}$, JV participated in the collection or generation of the study/project data. BCC, TDP, HK, QW, RR, YC, TL, EV, KP, $\mathrm{CD}, \mathrm{JV}$ performed the study/project. BCC, QW, RR, BK, SO, KP, JV contributed materials/analysis/reagent tools. BCC, TDP, RR, FV, EV, $\mathrm{SO}, \mathrm{KP}, \mathrm{CD}$, JV were involved in the analyses or interpretation of the data. JV was the principal investigator of the study.

\section{Acknowledgements}

The study was designed, funded, and interpreted by GlaxoSmithKline Biologicals SA in cooperation with an international steering committee. The authors thank the MAGRIT study committee and the independent data monitoring committee members, the patients who participated in the study, the investigators and their clinical teams for their contribution to the study and their support and care of patients; and all the GSK central and local teams who were involved in the study.

Writing assistance was provided by Joanne Wolter (Independent medical writer on behalf of GSK) and editorial and coordination assistance was provided by Houda Khamis (XPE Pharma \& Science on behalf of GSK).

\section{References}

1 Ferlay J, Steliarova-Foucher E, Lortet-Tieulent J, Rosso S, Coebergh JWW, Comber H, Forman D and Bray F: Cancer incidence and mortality patterns in europe: Estimates for 40 countries in 2012. Eur J Cancer 49(6): 1374-1403, 2013. PMID: 23485231. DOI: 10.1016/j.ejca.2012.12.027
2 Vansteenkiste JF, Cho BC, Vanakesa T, De Pas T, Zielinski M, Kim MS, Jassem J, Yoshimura M, Dahabreh J, Nakayama H, Havel L, Kondo H, Mitsudomi T, Zarogoulidis K, Gladkov OA, Udud K, Tada H, Hoffman H, Bugge A, Taylor P, Gonzalez EE, Liao ML, He J, Pujol J-L, Louahed J, Debois M, Brichard V, Debruyne C, Therasse P and Altorki N: Efficacy of the mage-a3 cancer immunotherapeutic as adjuvant therapy in patients with resected mage-a3-positive non-small-cell lung cancer (magrit): A randomised, double-blind, placebo-controlled, phase 3 trial. Lancet Oncol 17(6): 822-835, 2016. PMID: 27132212. DOI: 10.1016/S1470-2045(16)00099-1

3 Hsieh C-P, Hsieh M-J, Wu C-F, Fu J-Y, Liu Y-H, Wu Y-C, Yang $\mathrm{C}-\mathrm{T}$ and $\mathrm{Wu} \mathrm{C}-\mathrm{Y}$ : Prognostic factors in non-small cell lung cancer patients who received neoadjuvant therapy and curative resection. J Thorac Dis 8(7): 1477-1486, 2016. PMID: 27499934. DOI: $10.21037 /$ jtd.2016.05.57

4 Kiankhooy A, Taylor MD, LaPar DJ, Isbell JM, Lau CL, Kozower BD and Jones DR: Predictors of early recurrence for node-negative t 1 to $2 \mathrm{~b}$ non-small cell lung cancer. Ann Thorac Surg 98(4): 1175-1183, 2014. PMID: 25134863. DOI: 10.1016/ j.athoracsur.2014.05.061

5 Socinski MA, Obasaju C, Gandara D, Hirsch FR, Bonomi P, Bunn P, Kim ES, Langer CJ, Natale RB, Novello S, Paz-Ares L, Pérol M, Reck M, Ramalingam SS, Reynolds CH, Spigel DR, Stinchcombe TE, Wakelee H, Mayo $\mathrm{C}$ and Thatcher N: Clinicopathologic features of advanced squamous nsclc. J Thorac Oncol 11(9): 14111422, 2016. PMID: 27296106. DOI: 10.1016/j.jtho.2016.05.024

6 Ding N, Pang Z, Zhang X, Huang C, Yang Y, Liu Q and Du J: Prognostic and predictive effects of positive lymph node number or ratio in NSCLC. Sci Rep 7(1): 584, 2017. PMID: 28373661. DOI: 10.1038/s41598-017-00619-5

7. Tamura M, Matsumoto I, Saito D, Yoshida S, Takata M and Takemura H: Lymph node ratio as a prognostic factor in patients with pathological n2 non-small cell lung cancer. World J Surg Oncol 14(1): 295, 2016. PMID: 27884195. DOI: 10.1186/ s12957-016-1048-5

8 Zhang YK, Chai ZD, Tan LL, Wang ZY, Chen ZJ, Le HB and Zhu WY: Association of lymph node involvement with the prognosis of pathological t1 invasive non-small cell lung cancer. World J Surg Oncol 15(1): 64, 2017. PMID: 28302176. DOI: 10.1186/s12957-017-1098-3

9 Scott WJ, Howington J, Movsas B and American College of Chest Physicians: Treatment of stage II non-small cell lung cancer. Chest 123(1 Suppl): 188S-201S, 2003. PMID: 12527579.

10 Shi W, Zhang W, Sun H and Shao Y: Sleeve lobectomy versus pneumonectomy for non-small cell lung cancer: A meta-analysis. World J Surg Oncol 10: 265, 2012. PMID: 23231962. DOI: 10.1186/1477-7819-10-265

11 Linder A, Welim HB, Velehorschi W, Coche T, Gruselle O, D'Agostino D, Louahed J, Lehmann F and Brichard VG: Prognostic value of mage-a3 and prame gene expression in nonsmall-cell lung cancer (NSCLC). J Clin Oncol 30(15_suppl): 7056, 2012.
Received January 16, 2019

Revised February 8, 2019

Accepted February 18, 2019 